\title{
Income effects and physician labour supply: evidence from the threshold system in Ontario
}

\author{
Jasmin Kantarevic, Boris Kralj, and Darrel Weinkauf \\ Ontario Medical Association
}

Abstract. We examine a reform to the physician threshold system in Ontario that provides a unique opportunity to assess the effect of fee changes on physician behaviour, free from the biases that potentially affect simple time-series or cross-section inference. We find that: (1) the income effects of fee changes are small, but significant; (2) the income effect dominates the substitution effect only for a minority of services with relatively low prices and high volumes; and (3) the cross effects of fee changes tend to be significant only for services with relatively high prices and low volumes. JEL classification: I12, I18

Effets de revenu et offre de travail des médecins: résultats dérivés des opérations du système de seuils de revenus en usage en Ontario. Une réforme du système des seuils de revenus (au delà desquels les médecins sont pénalisés) a fourni une occasion en or de mesurer l'effet des changements de revenus sur le comportement du médecin, en évitant les biais qui potentiellement vicient les résultats dérivés des séries chronologiques ou des analyses transversales. On découvre que (1) les effets de revenus des changements de rémunération sont faibles mais significatifs; (2) l'effet de revenu domine l'effet de substitution seulement pour un petit nombre de services à faible prix et fort volume; et (3) les effets croisés des changements de rémunération tendent à être significatifs seulement pour les services dont le prix est relativement élevé et où il y a faible volume.

\section{Introduction}

Since 1960 the percentage of GDP spent on health care in Canada has almost doubled (OECD 2007). As the provincial governments struggle to control the rising

Kantarevic is also affiliated with IZA. We thank seminar participants at York and Wilfrid Laurier universities, and the 6th Annual Economics Research Symposium at the University of Saskatchewan for useful comments. We also thank John Barber for excellent research assistance. As usual, all errors are ours. Email: jasmin_kantarevic@oma.org 
costs of health care, payments to physicians come under increasing scrutiny. ${ }^{1} \mathrm{~A}$ significant portion of these payments is in the form of fees for services provided. ${ }^{2}$ Given the dominant role provincial governments play in setting medical fees, it is important to understand how physicians respond to fee changes. Economic theory suggests that the physician response depends on the relative strength of income and substitution effects of fee changes, which is a priori unknown. As a consequence, understanding how physicians respond to fee changes is ultimately an empirical question.

There are essentially two ways to identify the effect of fee changes on the provision of medical services. The first is to match variation in fees and service volumes across physicians. This is problematic, however, if changes in fees are correlated with other unobservable determinants of physician behaviour. The second is to match periodic changes in fees with variation in service volumes over time. In this approach, it can be difficult to distinguish secular trends from the effect of fee changes. In either case, the basic problem is the absence of a control group.

In this paper, we exploit a unique reform to the physician threshold system in Ontario to isolate the impact of fee changes on the provision of medical services. The threshold system is similar to an income tax system, where physicians are taxed for practice income that exceeds a specified threshold. Importantly, the system exempts physicians in designated sub-specialties and geographic locations from the threshold reductions. These exempted physicians form a promising control group needed to disentangle the impact of fee changes from the impact of other factors on physician behaviour.

There are two transparent sources of variation in fees in our study. The source of cross-sectional variation is the threshold system itself, because it exempts certain services from the threshold reductions. Specifically, the fee for a given service varies across physicians, depending on whether physician billings are below or above the threshold level. The source of time-series variation is the 1998 threshold reform we study. This reform turned many exempt services into non-exempt services, thereby reducing their effective fees if physician billings exceeded the threshold level. Both of these sources of variation are government policies that are plausibly exogenous to individual physicians.

The 1998 threshold reform is attractive to analyze because it did not affect any other parameters of the threshold system, such as the threshold levels or marginal reduction rates. This makes it easier to both predict the reform impact and interpret our results, holding other economic incentives in the threshold system constant. In addition, the reform affected a large number of services and physicians in many medical specialties, which improves our chances of detecting a behavioural response of physicians.

1 Over the last two decades, expenditures on physician services in Canada have accounted for around $15 \%$ of annual health care costs (Emery, Auld, and Lu 1999).

2 In 2003 the fee-for-service (FFS) payments in Ontario accounted for $84.3 \%$ of practice income of specialists and $87.1 \%$ of practice income of general practitioners (OMA Human Resources Committee, Survey of Ontario Physicians 2003). 


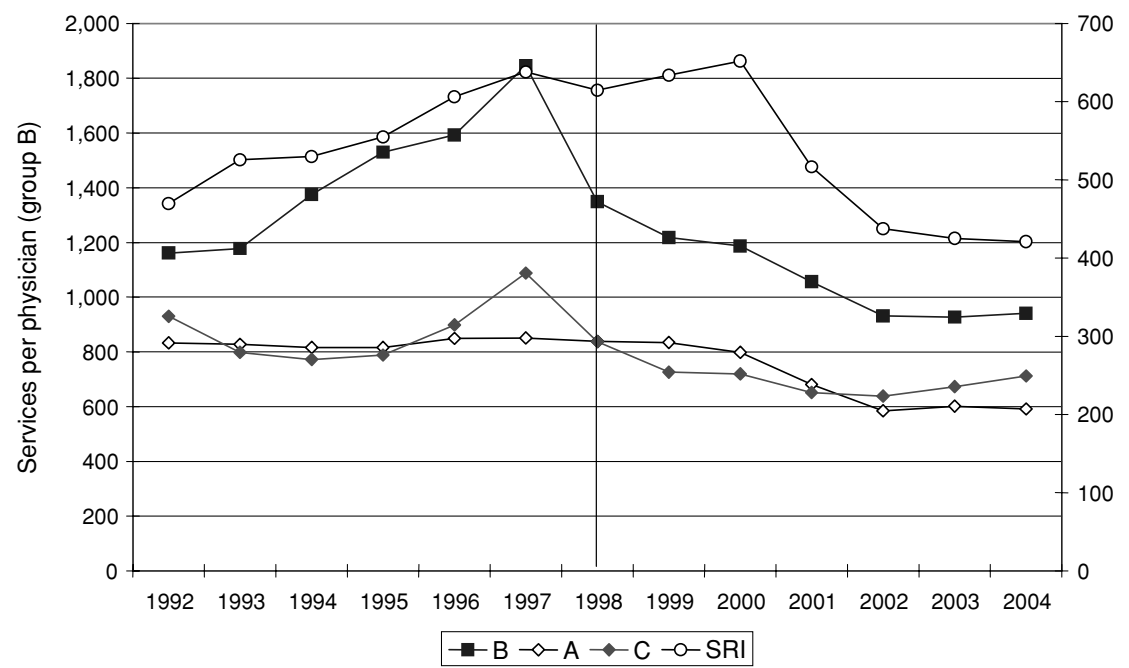

FIGURE 1 Exempt services per physician, 1992-2004

NOTE: The sample includes physicians who provided some exempt services over the 1992-2004 period and did not change their exemption status between 1997 and 1998.

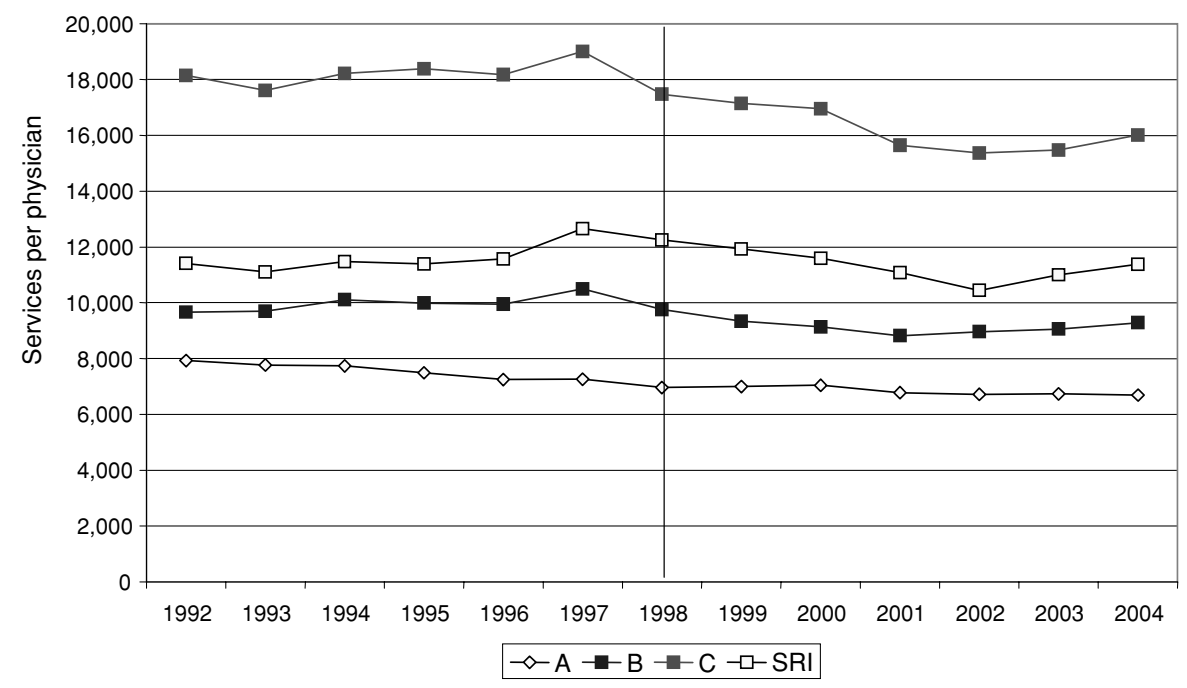

FIGURE 2 Non-exempt services per physician, 1992-2004

NOTE: The sample includes physicians who provided some exempt services over the 1992-2004 period and did not change their exemption status between 1997 and 1998.

Preliminary evidence of the impact of the 1998 threshold reform is presented in figures 1 and 2. Figure 1 shows services that were exempt prior to the reform but non-exempt after the reform, while figure 2 shows services that were non-exempt both before and after the reform. In the figures, SRI represents the control group 
of physicians who are exempted from the threshold system, while A, B, and C represent three treatment groups of physicians. The assignment of physicians to the treatment groups is based on the expected impact of 1998 reform, which we discuss in section 3. For now, note that figure 1 shows a significant dip in 1998 for physicians in groups $\mathrm{B}$ and $\mathrm{C}$ and no significant change for physicians in groups A and SRI, while figure 2 does not reveal a significant change for any group of physicians relative to the SRI control group. These results indicate that the reform induced (some) physicians to reduce their provision of initially exempt services, but it had no significant spillover effects on non-exempt services. Therefore, it appears that the reform was quite successful in achieving the government objective of reducing volumes of targeted services without adversely affecting other services.

To relate these findings to the literature on physician labour supply, we exploit the predicted variation in the reform impact across treatment groups to formulate an empirical model in which income and substitution effects can be separately identified. Our more important results are as follows. First, we find that the income effect is small but significant. This result confirms earlier findings (e.g., Rizzo and Blumenthal 1994) that neither the two polar cases of no income effects (the profit maximization hypothesis) nor infinitely large income effects (the literal target income hypothesis) adequately describe physician behaviour.

Second, we find that the income effect tends to be smaller than the compensated price effect for all exempted services, while the perverse case of negatively sloped supply curves occurs only among a minority of non-exempt services. Furthermore, the compensated cross-price effect tends to be significant only for the exempt services. Given that exempt services have higher prices and smaller volumes than non-exempt services, our results suggest that these easily measurable characteristics of services may be a useful guide for future policy decisions.

Our study contributes to the large literature that examines the physician response to changes in medical fees. A shortcoming of earlier studies in this literature is the lack of measures of income effects in their empirical specifications (e.g., Hurley, Labelle, and Rice 1990). Our work is more closely related to recent studies of the effect of the Omnibus Budget Reconciliation Acts (OBRA) in the United States that attempt to separately estimate income and substitution effects (e.g., Mitchell, Hadley, and Gaskin 2000, 2002; Rice et al. 1999; Tai-Seale, Rice, and Stearns 1998; Yip 1998). In addition, our study is among the first attempts to use a treatment-control approach to identify the impact of fee changes on the provision of medical services. ${ }^{3}$ This approach provides a more transparent source of identification than either the cross-sectional or the time-series variation alone. We also contribute to this literature by using a larger and more representative sample of physician population (all fee-for-service physicians in Ontario)

3 Rice (1983) also examined an experiment that resulted from an administrative change in the Medicare program that led to substantial increases in payments for rural physicians but not for those in urban areas. The results indicated that the complexity and quantity of selected services provided by urban physicians increased relative to that of rural physicians. 
than in most previous studies. This facilitates comparison of price elasticities for a wide variety of medical services and different groups of physicians using the same methodological approach. Lastly, our study of the Ontario health care system offers two additional benefits. First, Ontario patients face no out-of-pocket charges for insured services because health care is provided under a publicly funded insurance scheme. Therefore, demand for medical services is unlikely to be affected by changes in the fee schedule, and changes in utilization can be interpreted as being primarily supplier driven. Second, each insured service in Ontario is remunerated using the same fee schedule, and individual physicians have virtually no discretion over the fees they charge. Therefore, a primary response of physicians to fee changes is an adjustment in the type and number of services provided.

The paper is organized as follows. The next section briefly describes the evolution of the threshold system in Ontario. Section 3 presents the theoretical analysis of the reform impact, while section 4 discusses our empirical strategy. Section 5 describes the data, and section 6 discusses the results. We conclude in section 7. Appendices A and B, posted on the Journal's website, contain detailed discussion of our theoretical model and additional sensitivity tests of the empirical results.

\section{Threshold system in Ontario}

In Ontario, as in other Canadian provinces, health insurance coverage is universal and physicians are compensated directly by the provincial government for providing insured services. The government regulates medical fees and implements policies that potentially affect physician compensation, their recruitment and retention, and the type of medical services they provide.

One such policy is the physician threshold system. The objective of the system is to limit increases in physician compensation by taxing physicians for billings that exceed specified thresholds. The system is similar to an income tax system: it specifies the number and levels of income thresholds, the marginal tax rate for each threshold, and exemptions that apply to specific services or groups of physicians.

The evolution of the system in Ontario is presented in table $1 .{ }^{4}$ When the system was introduced in 1991, physicians were taxed at a rate of one-third if their taxable billings exceeded $\mathrm{C} \$ 400,000$ and at a rate of two-thirds if their taxable billings exceeded $C \$ 475,000$. Included in the taxable billings were all medical services rendered by physicians. ${ }^{5}$ Physicians practising in underserved areas and in unique medical subspecialties were exempted from the system under a program

4 For a detailed description of physician threshold systems in other Canadian provinces, see Dowdall and Ramchandar (1999).

5 The threshold tax is a tax on gross income before most practice expenses are subtracted. Technical fees, which cover certain non-physician costs such as expenses on medical equipment and supplies for diagnostic services, are excluded from the threshold calculations. 
TABLE 1

Threshold system in Ontario, 1991-2005

\begin{tabular}{|c|c|c|c|c|c|}
\hline Effective date & Applicability & $\begin{array}{l}1 / 3 \\
\text { reduction } \\
\text { threshold }\end{array}$ & $\begin{array}{l}2 / 3 \\
\text { reduction } \\
\text { threshold }\end{array}$ & $\begin{array}{l}3 / 4 \\
\text { reduction } \\
\text { threshold }\end{array}$ & Exempted services \\
\hline 1 April 1991 & All physicians & $\$ 400,000$ & $\$ 475,000$ & - & Technical fees \\
\hline 1 October 1992 & All physicians & $\$ 402,000$ & $\$ 477,000$ & - & Technical fees \\
\hline 1 April 1993 & All physicians & $\$ 404,000$ & $\$ 479,750$ & - & Technical fees \\
\hline 1 April1996 & By Specialty & \multicolumn{2}{|c|}{ Specialty specific } & & $\begin{array}{l}\text { Technical fees, selected } \\
\text { professional fees }\end{array}$ \\
\hline 1 January 1997 & GPs & $\$ 300,000$ & $\$ 337,500$ & $\$ 412,500$ & No change \\
\hline & Specialists & $\$ 380,000$ & $\$ 417,500$ & $\$ 492,500$ & \\
\hline 1 April 1998 & $\begin{array}{l}\text { GPs } \\
\text { Specialists }\end{array}$ & $\begin{array}{l}\text { No change } \\
\text { No change }\end{array}$ & $\begin{array}{l}\text { No change } \\
\text { No change }\end{array}$ & $\begin{array}{l}\text { No change } \\
\text { No change }\end{array}$ & $\begin{array}{l}\text { Changes to } 1996 \text { exempted } \\
\text { technical fees and selected } \\
\text { professional fees }\end{array}$ \\
\hline 1 April 1999 & GPs & $\$ 320,000$ & $\$ 345,000$ & $\$ 370,000$ & No change \\
\hline & Specialists & $\$ 400,000$ & $\$ 425,000$ & $\$ 450,000$ & \\
\hline 1 April 2000 & GPs & $\$ 330,000$ & $\$ 355,000$ & $\$ 380,000$ & No change \\
\hline & Specialists & $\$ 410,000$ & $\$ 435,000$ & $\$ 460,000$ & \\
\hline 1 April 2002 & All physicians & - & $\$ 455,000$ & - & $\begin{array}{l}\text { Additional after-hours } \\
\text { non-elective hospital } \\
\text { services, selected acute } \\
\text { care hospital in-patient } \\
\text { services, selected critical } \\
\text { care services }\end{array}$ \\
\hline April 1, 2005 & All physicians & \multicolumn{3}{|c|}{ The threshold system eliminated. } & \\
\hline
\end{tabular}

NOTE: Professional fees are fees for medical services rendered by physicians, while technical fees cover certain non-physician costs such as expenses for medical equipment and supplies for diagnostic services.

known as the Specialist Retention Initiative (SRI) program. The SRI program was intended to partially offset the effect of the threshold system by discouraging specialists from leaving the province and to redress geographical mal-distribution of physicians.

In the following four years, the threshold levels increased in parallel with the average increase in medical fees. A major reform occurred in 1996, when the government made thresholds specific to each medical specialty and at levels significantly lower than in previous years. To address potential adverse effects of this reform, the government identified the services to be exempted from the system, using criteria that included services urgently requiring protection and services with high potential to be discontinued or where shortages currently exist. Examples of these services include cardiac surgery, cataract and retinal surgeries, labour and delivery, and transplants.

The provisions of the 1996 reform were partially reversed over the following two years. By the end of 1996 a new system had abandoned thresholds specific to each medical specialty and instead differentiated between general practitioners and specialists only. Another major reform occurred in 1998 - the reform on 
which we focus in this study - when most services exempted by the 1996 reform were now included in the taxable billings. ${ }^{6}$

Over the next four years the system remained stable, increases in thresholds matching average increases in medical fees. The latest significant reform occurred in 2002, when government imposed a single threshold for all medical specialties and exempted certain hospital and critical care services from the system. Finally, the physician threshold system was eliminated altogether in 2005.

The threshold system in Ontario thus has undergone many reforms over the fourteen years of its life. These reforms provide a unique opportunity to evaluate the impact of the threshold system on various outcomes of interest, such as the composition of services physicians provide. As mentioned earlier, we chose to focus on the 1998 reform for two main reasons. First, it is the reform that affected only one parameter of the system (namely, the set of exempt services). This feature of the reform makes it easier both to discuss its predicted impact and to interpret the empirical results, holding other parameters of the system constant. Second, the 1998 reform affected close to 90 medical services, whose total value in 1997 represented about $3 \%$ of total fee-for-service payments. In addition, about one-third of all physicians provided some exempt services prior to the reform. This potentially widespread impact of the reform improves our chances to detect behavioural responses of physicians to changes in economic incentives.

\section{Expected impact of the threshold reform}

To analyze the impact of the 1998 reform, we use a simplified version of the physician labour supply model of McGuire and Pauly (1991), extended to incorporate a piece-wise linear budget constraint arising from the threshold system. ${ }^{7}$ Specifically, the physician problem before the reform can be stated as follows:

$$
\begin{aligned}
& u=u(c, l) \\
& c=p_{1} x_{1}+p_{2} x_{2}+m \quad \text { if } p_{1} x_{1} \leq \bar{y} \\
& c=\bar{y}+(1-t)\left(p_{1} x_{1}-\bar{y}\right)+p_{2} x_{2}+m \text { if } p_{1} x_{1}>\bar{y} \\
& x_{1}=x_{1}\left(h_{1}\right), \quad x_{2}=x_{2}\left(h_{2}\right) \\
& 24=l+h_{1}+h_{2} .
\end{aligned}
$$

6 Details of the 1998 threshold reform are available from the Ontario Health Insurance Plan Bulletin 4309.

7 For excellent reviews of labour supply models with non-linear budget constraints, see Hausman (1985) and Moffitt (1986, 1990). 
Equation (1) describes physician preferences. Physicians in this model derive utility $(u)$ from leisure $(l)$ and consumption $(c)$. We assume that the marginal utilities are positive $\left(u_{c}>0, u_{l}>0\right)$ and diminishing $\left(u_{c c} \leq 0, u_{l l} \leq 0\right)$, and that the utility function is additively separable $\left(u_{l c}=0\right)$. Equation (2) describes the physician budget constraint. Physician consumption is constrained by the sum of medical practice income and non-labour income $(m)$. Practice income consists of revenues from two types of medical service, $x_{1}$ and $x_{2}$, with respective prices of $p_{1}$ and $p_{2}{ }^{8,9}$ The difference between the two types of service is that income from $x_{1}$ above threshold $\bar{y}$ is taxed at rate $t$, while income from $x_{2}$ services is not taxed. This feature of the threshold system splits the budget constraint into two segments, below and above the threshold, where each segment is linear but the return to nonexempt services differs between the segments. Equation (3) describes the available technology for transforming physician time inputs $\left(h_{1}\right.$ and $\left.h_{2}\right)$ into each type of medical service. We assume that the marginal products are positive $\left(x_{1}^{\prime}>0, x_{2}^{\prime}>\right.$ 0 ) but strictly diminishing $\left(x_{1}^{\prime \prime}<0, x_{2}^{\prime \prime}<0\right)$. The latter assumption ensures an interior solution and is consistent with most empirical evidence (e.g., Reinhardt 1972; Brown; Thurnton 1998). Lastly, equation (4) describes the physician time constraint.

The physician's problem is to allocate her total time between leisure and provision of services to maximize her utility, subject to the budget constraint and the production technology. The solution involves two steps. In the first step, the physician finds her optimal allocation of time for each segment of the budget set. Given this allocation, the physician then chooses the segment that provides her with greater utility in the second step.

Consider now the impact of the 1998 threshold reform. The reform turned exempt services $x_{2}$ into non-exempt services, lowering their price to $(1-t) p_{2}$ if physician total practice income exceeded the threshold. Therefore, the new budget constraint is

$$
\begin{aligned}
& c=p_{1} x_{1}+p_{2} x_{2}+m \quad \text { if } p_{1} x_{1}+p_{2} x_{2} \leq \bar{y} \\
& c=\bar{y}+(1-t)\left(p_{1} x_{1}+p_{2} x_{2}-\bar{y}\right)+m \text { if } p_{1} x_{1}+p_{2} x_{2}>\bar{y} .
\end{aligned}
$$

The impact of this change in the budget constraint depends on physician initial volumes of each type of service (denoted by $x_{1}^{0}$ and $x_{2}^{0}$ ). Specifically, we can distinguish between three groups of physicians: physicians with volumes below the threshold both before and after the reform (group A), physicians who were already above the threshold before the reform (group C), and physicians who were below the threshold before the reform but would be above the threshold

$8 p_{1}$ and $p_{2}$ can be interpreted as the margins of actual fees over the constant marginal cost of non-physician inputs.

9 We assume that each individual physician is a price taker but has some market power in setting the quantity of services provided. The price-taking assumption is consistent with physicians' having influence on medical fees through their collective bargaining power when the physician group is large (e.g., over 20,000 physicians in Ontario). The physician quantity-setting power may arise, among other reasons, because medical services are non-tradeable (McGuire 2000). 
after the reform if they did not change their practice style (group B). The impact of the 1998 reform on prices and virtual non-labour income $(\hat{m})$ for these three groups of physicians can be summarized as follows:

Impact of 1998 Reform on

\begin{tabular}{lllll}
\cline { 4 - 5 } Group & Initial budget constraint & $\Delta p_{1}$ & $\Delta p_{2}$ & $\Delta \hat{m}$ \\
\hline A & $p_{1} x_{1}^{0}+p_{2} x_{2}^{0}<\bar{y}$ & 0 & 0 & 0 \\
B & $p_{1} x_{1}^{0}<\bar{y}<p_{1} x_{1}^{0}+p_{2} x_{2}^{0}$ & $-t p_{1}$ & $-t p_{2}$ & $+t \bar{y}$ \\
C & $p_{1} x_{1}^{0}>\bar{y}$ & 0 & $-t p_{2}$ & 0
\end{tabular}

Therefore, physicians in group A should not be affected at all by the 1998 reform. For physicians in group B, the reform reduced effective prices of both types of services and increased their virtual non-practice income, while for physicians in group $\mathrm{C}$ the reform reduced the effective price only of exempt services.

The impact of the reform on group $\mathrm{C}$ physicians represents the conceptual experiment of changing the price of exempt services, while holding the price of non-exempt services and non-labour income constant. ${ }^{10}$ The expected change in volumes of exempt and non-exempt services is in general ambiguous and we refer the interested reader to appendix A for details. We discuss here two polar cases that have received considerable attention in the literature: the profit maximization case, with no income effects, and the literal target income case, with strong income effects. ${ }^{11}$

With no income effects, the own-price effect is unambiguously positive and the cross-price effect is negative. Therefore, the profit maximization hypothesis implies that the 1998 reform will induce physicians in group C to reduce their supply of exempt services and increase their supply of non-exempt services. In contrast, with strong income effects, the physician response depends not only on the nature of physician preferences but also on the characteristics of services. In our sample, the exempt services are services with relatively higher prices and lower volumes than the non-exempt services. ${ }^{12}$ Numerical simulations in McGuire and Pauly (1991) suggest that in this case both the own-price effect and the cross-price effect will be negative. Therefore, the literal income target hypothesis implies that physicians in group $\mathrm{C}$ will likely increase their provision of both types of services.

10 The analysis for physicians in group B is more complex because the reform reduced effective prices of both types of services and increased their non-practice income. In the next section, we discuss more precisely the impact for physicians in this group.

11 In the literature, the profit-maximization case is defined as the case where $u_{\mathrm{CC}} \rightarrow 0$ and the literal target income hypothesis as the case where $u_{\mathrm{CC}} \rightarrow-\infty$. See, for example, McGuire and Pauly (1991) and McGuire (2000).

12 In our sample, the average price is $\$ 103$ for exempt services and $\$ 26$ for non-exempt services. In contrast, the average number of services per physician is 307 for exempt services and 10,005 for non- exempt services. 
The actual physician behaviour is likely to fall in between the profit maximization and literal income target cases. Ultimately, it remains an empirical question to determine the relative strength of the income and substitution effects.

\section{Empirical strategy}

To formulate an empirical model in which the substitution and income effect can be separately identified, we exploit the variation in the expected impact of the threshold reform on different groups of physicians. We start with the nonexempt services. The supply function for these services can be written as $x_{1}\left(p_{1}\right.$, $\left.p_{2}, m\right)$. The first-order Taylor approximation around the pre-reform prices and non-labour income yields

$$
\Delta x_{1}=\frac{\partial x_{1}}{\partial p_{1}} \Delta p_{1}+\frac{\partial x_{1}}{\partial p_{2}} \Delta p_{2}+\frac{\partial x_{1}}{\partial m} \Delta m
$$

Using the Slutsky-type equation to decompose the uncompensated price changes into income and substitution effects, we can write

$$
\begin{aligned}
\Delta x_{1} & =\left(a+c x_{1}\right) \Delta p_{1}+\left(b+c x_{2}\right) \Delta p_{2}+c \Delta m \\
& =a \Delta p_{1}+b \Delta p_{2}+c\left(x_{1} \Delta p_{1}+x_{2} \Delta p_{2}+\Delta m\right),
\end{aligned}
$$

where $a \geq 0$ is the compensated own-price effect, $b \leq 0$ is the compensated crossprice effect, and $c \leq 0$ is the income effect. ${ }^{13}$

Changes in prices and non-labour income vary in a predictable way across different physician groups, as discussed in the previous section, and equation (6) can be written for each group as follows:

$$
\begin{aligned}
& \Delta x_{1}(A)=0 \\
& \Delta x_{1}(B)=-a t p_{1}^{0}-b t p_{2}^{0}-c\left[t\left(p_{1}^{0} x_{1}^{0}+p_{2}^{0} x_{2}^{0}-\bar{y}\right)\right], \\
& \Delta x_{1}(C)=-b t p_{2}^{0}-c t p_{2}^{0} x_{2}^{0} .
\end{aligned}
$$

Equation (7) can now be used to formulate the following regression model:

$$
\begin{aligned}
x_{i t}^{1}= & \alpha+\alpha_{A} \times \text { Group }_{i}+\alpha_{B} \times \text { Group }_{i}+\alpha_{C} \times \text { Group }_{i}+\delta \times \text { Post }_{t} \\
& +\beta_{A} \times \text { Group }_{i} \times \text { Post }_{t}+\beta_{B} \times \text { Group }_{i} \times \text { Post }_{t} \\
& +\beta_{C} \times \text { Group }_{i} \times \text { Post }_{t}+\gamma \times y_{i} \times \text { Post }_{t}+\varepsilon_{i t},
\end{aligned}
$$

where $i$ indexes physicians and $t$ indexes time, Group $X$ is an indicator for physicians in group $X$ (the omitted category is the SRI group of physicians), Post

13 For details, please refer to appendix A. 
is an indicator for the post-reform period, and $y$ measures the expected change in physician income: $y_{i}=0$ for physicians in group $\mathrm{A},-t\left(p_{1}^{0} x_{1}^{0}+p_{2}^{0} x_{2}^{0}-\bar{y}\right)$ for physicians in group $\mathrm{B}$, and $-t p_{2}^{0} x_{2}^{0}$ for physicians in group $\mathrm{C}$.

In this model, $\gamma$ theoretically identifies the income effect $c, \beta_{C}$ identifies $b t p_{2}^{0}$, and $\beta_{B}-\beta_{C}$ identifies $-a t p_{1}^{0}$. Therefore, the theory places the following restrictions on the model parameters: $\beta_{A}=0$ (since physicians in group A should not be affected by the reform); $\gamma \leq 0$ (since the income effect is non-positive); $\beta_{C} \geq 0$ (since the cross-price effect is non-positive); and $\beta_{B}-\beta_{C} \leq 0$ (since the own-price effect is non-negative).

A similar approach can be used for exempt services $x_{2}$, with the difference that $a$ now represents the cross-price effect (since it multiplies $\Delta p_{1}$ ) and $b$ represents the own-price effect (since it multiplies $\Delta p_{2}$ ). In this model, $\gamma$ identifies the income effect $c, \beta_{C}$ identifies $-b t p_{2}^{0}$, and $\beta_{B}-\beta_{C}$ identifies $-a t p_{1}^{0}$. Therefore, the parameter restrictions in the model for exempt services are: $\beta_{A}=0 ; \gamma \leq 0$, $\beta_{C} \leq 0$; and $\beta_{B}-\beta_{C} \geq 0$.

The regression model (8) and the corresponding model for exempt services form the basis for our empirical work. The dependent variable in these models is the number of services provided by physicians. We use both the raw count of services as well as the relative value units that account for the time requirement and intensity of performing each service. ${ }^{14}$ The latter approach partially addresses the concern that a simple aggregation of services is not meaningful if services within each group are heterogeneous. To further address the aggregation bias concern, we also estimate models for specific types of exempt services based on their similarity (e.g., various types of transplants as a single group). For non-exempt services, we define groups of services based on the Ontario Schedule of Benefits classification. ${ }^{15}$ Because our dependent variable is discrete and non-negative, we use the negative binomial model in most of our specifications. The model is more appropriate than the Poisson model if the variance of the dependent variable exceeds its mean, and this over-dispersion is due to individual heterogeneity (e.g., Grootendorst 1995). As a specification check, we also report results from the corresponding Poisson models.

Our main set of control variables includes physician age, gender, medical specialty, and the geographic location of practice. As a robustness check, we also estimate models with fixed physician effects to account for unobserved but timeinvariant physician characteristics.

14 The relative value units (RVUs) come from the report prepared by the Resource-Based Relative Value Schedule (RBRVS) Commission of Ontario in 2002 based on a methodology similar to that for the Medicare Relative Value Schedule in the United States. The RVU for each service is the product of time and intensity components. The time component measures total physician time, which includes pre, intra-, and post-service time. The intensity component measures knowledge and judgment, communication and interpersonal skill, technical skill, and risk stress. One limitation of using RVUs is that the recommendations of the RBRVS Commission were not implemented in Ontario.

15 The Schedule of Benefits is the official physician manual that provides description of all insured services in Ontario and their fees. 
Our identification strategy relies on the difference-in-difference approach, where the SRI physicians form the control group, while other physicians form the treatment group. The main benefit of this approach is that it may difference out the impact of unobserved, time-varying factors that may affect the composition of services physicians provide. The validity of this approach depends crucially on the assumption that these unobserved variables do not change differently for the SRI physicians and physicians in other groups. On the policy level, our research of the Ontario Ministry of Health and Long-Term Care policy bulletins did not reveal any changes in economic incentives that affected only the SRI physicians during the study period. On the physician level, as figures 1 and 2 show, the SRI physicians and physicians in treatment groups experienced similar trends in the provision of exempt and non-exempt services prior to the 1998 reform. These two points provide some justification for using the SRI physicians as a control group. To further validate the comparability of SRI physicians to other physicians, we conduct two additional tests. The first test is based on the idea that physicians with similar observed characteristics are likely to have similar unobserved characteristics. Therefore, we estimate the models separately for different groups of physicians based on their gender, broad medical specialty, age, and geographic location. We also estimate a matching score for each physician based on the predicted probability that a physician is in the SRI group in 1997, and then we estimate the models for samples with different cut-off points of the matching score. The idea here is that physicians with successively higher cut-off points should be more similar to physicians in the SRI control group, which should improve our estimates. Second, we use the distinction between the full SRI physicians (all services exempted) and partial SRI physicians (only selected services exempted). Since the latter group is a hybrid between the treatment and control groups, we test the proposition that the reform impact should be smaller when the partial SRI physicians are included in the control group.

The validity of the difference-in-difference approach also relies on the assumption of constant composition of treatment and control groups, or at least a composition that does not vary systematically with the expected impact of the reform. However, this assumption is not convincing in our study because physicians most affected by the reform had strong incentives to switch to the control group and avoid reduction in their income. We use two methods to address this concern. ${ }^{16}$ The first and straightforward method is to exclude 'switchers' between the treatment and control groups from the sample. The limitation of this method is that it focuses only on the partial impact of the reform (i.e., the provision of services), neglecting the impact that the reform may have on other behaviour of physicians such as retirement, out of province migration, and changes in physician exemption status. The second method is to include 'switchers' in the sample but

16 In the difference-in-difference framework, recent studies that address composition bias include Autour, Donohue, and Schwab (2003), Autor and Scarborough (2004), Beegle and Stock (2003), and Mas (2004). 
as a part of the control group. The idea here is that these physicians did respond to the reform by obtaining their SRI status but presumably not by changing their provision of services. If this were the case, the switchers may be a better control group than physicians who remained in the SRI group both before and after the reform.

\section{Data}

The data are taken from the Ontario Health Insurance Plan (OHIP) administrative database for the fiscal years 1997 and 1998. The 1998 reform was announced and became effective in the first month of the fiscal year 1998, so our sample includes one year before the reform and one year after the reform. As discussed earlier, the only difference in the threshold system between these two years is that some services were exempt in 1997 but not in 1998.

The OHIP data have several advantages for analyzing the 1998 reform. First, the data include all fee-for-service physicians in Ontario, a group that forms the entire population affected by the threshold system. Second, the data include the fee code and amount paid for each service at the physician level. Such information is necessary to precisely assign physicians to the three treatment groups A, B, and C. Third, the data also identify SRI physicians, a promising control group that is paid on the fee-for-service basis but is exempted from the threshold system.

We assign physicians to the three treatment groups based on the type and number of services provided in 1997 by using the old (1997) and the new (1998) system rules. Specifically, if the taxable billings calculated using the old and the new rules did not exceed the minimum threshold level, a physician was assigned to group A; if the taxable billings calculated using the old rules did not exceed the minimum threshold level, but exceeded the minimum threshold level using the new rules, a physician was assigned to group B; and if the taxable billings calculated using the old and the new rules exceeded the minimum threshold level, a physician was assigned to group $\mathrm{C}$. We also experiment with assigning physicians to groups based on the type and number of medical services in 1996 to account for possible measurement errors in billings and non-random assignment of physicians to groups. For example, our assignment may be imprecise if the actual and desired choices of services are not identical because physicians make optimization errors, or if there are measurement errors in our data. In addition, if physicians chose their provision of medical services in 1997 anticipating the 1998 reform, our assignment will be non-random and estimates of the impact of the 1998 reform will be biased. Instrumenting for the assignment based on the physicians' historical practice styles potentially addresses both of these problems.

Our main sample includes physicians who were present in both 1997 and 1998. We also experiment with including physicians who were present only in 1997 to examine the possibility that the reform induced some physicians to leave Ontario 
or cease to practice. ${ }^{17}$ This is yet another potential behavioural response of physicians to the reform, in addition to changing the practice style and exemption status that were discussed before. Further, we focus on physicians who were providers of exempt services in at least one year over the 1992 to 2004 period to differentiate between physicians who are non-providers by their choice and physicians who lack knowledge, expertise, or technology to provide these services. As a robustness check, we also estimate models with all physicians in the sample but use the zero-inflated models to statistically account for the non-provider physicians (Greene 1994; Grootendorst 1995; Jones 2000).

Our main sample includes 5,623 physicians (11,246 physician-year observations), or about one-third of all physicians in Ontario in 1997. Descriptive statistics of the sample are presented in table 2. Two points are worth noting here. First, most physicians (about $80 \%$ ) belong to group A, which is also the group with the highest fraction of female physicians and general practitioners. Second, most physicians in groups B and SRI are specialists, a large share of whose income is derived from exempt services (about one-third compared with about $5 \%$ for other physicians).

Table 3 shows the percentage changes in services per physician between 1997 and 1998, by the exemption type of service and for each treatment group of physicians. The upper panel presents the results when all provider physicians are included in the sample. For physicians in group A, the percentage change for both exempt and non-exempt services is relatively small ( $-5 \%$ and $-4 \%$, respectively). For physicians in groups $\mathrm{B}$ and $\mathrm{C}$, the percentage change for exempt services is large and negative $(-35 \%$ and $-37 \%$, respectively), but relatively small for nonexempt services $(-2 \%$ and $-7 \%$, respectively). Lastly, for the SRI physicians, the percentage change for exempt services is positive and large $(75 \%)$, while for non-exempt services it is negative and large $(-21 \%)$.

As discussed earlier, these results may not represent the impact of the 1998 reform because physicians affected by the reform had strong incentives to switch to the SRI group and thus be exempted from the threshold system altogether. We document this possibility in table 1 of appendix B, which presents the transition of physicians to the below threshold group, the above threshold group, and the SRI group following the 1998 reform. Most of the physicians in group A remained in the below threshold group. However, about $31 \%$ of the physicians in group B and $8 \%$ of the physicians in group C switched to the SRI group. This result is interesting, as it illustrates that physicians usually have more than one margin to respond to changes in economic incentives. In this case, it seems that many physicians eligible for the SRI status (based on their medical specialty and

17 In 1998 the attrition rate of physicians (3.55\%) was not significantly different from the average attrition rate in the previous five years $(3.91 \%)$. In addition, the average age, the proportion of males, and the proportion of general practitioners who left the health care system is not significantly different in 1998 compared with the previous five years. For details, see table 10 in appendix B. 
TABLE 2

Descriptive statistics of the sample

\begin{tabular}{|c|c|c|c|c|}
\hline & \multicolumn{4}{|l|}{ Year 1997} \\
\hline & Group A & Group B & Group C & SRI \\
\hline \multicolumn{5}{|l|}{ Physicians' characteristics } \\
\hline Age & 49.8 & 48.5 & 48.2 & 48.7 \\
\hline$\%$ Male & $78 \%$ & $91 \%$ & $94 \%$ & $99 \%$ \\
\hline$\%$ General practitioner & $70 \%$ & $9 \%$ & $64 \%$ & $35 \%$ \\
\hline$\%$ Practising in Toronto & $22 \%$ & $32 \%$ & $30 \%$ & $24 \%$ \\
\hline \multicolumn{5}{|l|}{ Medical services per physician } \\
\hline All medical services & 9,049 & 12,529 & 20,119 & 14,869 \\
\hline Services exempted in 1997 & 253 & 2,024 & 430 & 521 \\
\hline Non-exempt services & 8,795 & 10,506 & 19,689 & 14,348 \\
\hline \multicolumn{5}{|l|}{ Income sources } \\
\hline$\%$ from exempt services & $6 \%$ & $37 \%$ & $5 \%$ & $23 \%$ \\
\hline Observations (total $=5,622)$ & 4,531 & 317 & 688 & 86 \\
\hline \multirow[t]{3}{*}{ Percentage of total observations } & $81 \%$ & $6 \%$ & $12 \%$ & $2 \%$ \\
\hline & \multicolumn{4}{|l|}{ Year 1998} \\
\hline & Group A & Group B & Group C & SRI \\
\hline \multicolumn{5}{|l|}{ Physicians' characteristics } \\
\hline Age & 50.8 & 50.2 & 49.2 & 48.5 \\
\hline$\%$ Male & $78 \%$ & $91 \%$ & $94 \%$ & $95 \%$ \\
\hline$\%$ General practitioner & $70 \%$ & $13 \%$ & $67 \%$ & $16 \%$ \\
\hline$\%$ Practising in Toronto & $22 \%$ & $36 \%$ & $32 \%$ & $22 \%$ \\
\hline \multicolumn{5}{|l|}{ Medical services per physician } \\
\hline All medical services & 8,689 & 11,651 & 18,628 & 12,238 \\
\hline Services exempted in 1997 & 240 & 1,320 & 273 & 913 \\
\hline Non-exempted services & 8,449 & 10,332 & 18,355 & 11,325 \\
\hline \multicolumn{5}{|l|}{ Income sources } \\
\hline$\%$ from exempt services & $6 \%$ & $29 \%$ & $2 \%$ & $28 \%$ \\
\hline Observations (total $=5,622)$ & 4,513 & 222 & 637 & 250 \\
\hline Percentage of total observations & $80 \%$ & $4 \%$ & $11 \%$ & $4 \%$ \\
\hline
\end{tabular}

\section{NOTES:}

Definitions of physician groups are provided in the text. The sample includes physicians who are present in both 1997 and 1998 and who provided some exempt services in at least one year from 1992 to 2004. The percentage of total observations may not add to 100 due to rounding.

DATA SOURCE: Ontario Health Insurance Plan (OHIP) claims database, fiscal years 1997 and 1998.

location of practice) decided to apply only when the SRI status had real economic consequences for them.

To address the problem of changing composition of treatment and control groups, we examined the effect of removing switchers from the sample. The results are presented in the lower panel of table 3. The most striking result is that the percentage change for exempt services for groups $\mathrm{B}$ and $\mathrm{C}$ is now significantly smaller than it was in the original sample. In addition, the percentage change for 
TABLE 3

Changes in medical services per physician, 1998 versus 1997

\begin{tabular}{lllll}
\hline Including 'SRI Switchers' & Group A & Group B & Group C & SRI \\
\hline All medical services & $-4.0 \%$ & $-7.0 \%$ & $-7.4 \%$ & $-17.7 \%$ \\
$\quad$ Services exempted in 1997 & $-5.3 \%$ & $-34.8 \%$ & $-36.6 \%$ & $75.2 \%$ \\
$\quad$ Non-exempted services & $-3.9 \%$ & $-1.7 \%$ & $-6.8 \%$ & $-21.1 \%$ \\
Number of physicians in 1997 (total =5,623) & 4,532 & 317 & 688 & 86 \\
Number of physicians in 1998 (total =5,623) & 4,514 & 222 & 637 & 250 \\
\hline Excluding 'SRI switchers' & Group A & Group B & Group C & SRI \\
\hline All medical services & $-4.1 \%$ & $-10.0 \%$ & $-8.8 \%$ & $-4.7 \%$ \\
$\quad$ Services exempted in 1997 & $0.3 \%$ & $-27.3 \%$ & $-24.3 \%$ & $-1.8 \%$ \\
$\quad$ Non-exempted services & $-4.2 \%$ & $-7.2 \%$ & $-8.5 \%$ & $-4.8 \%$ \\
Number of physicians (total $=5,431)$ & 4,508 & 220 & 631 & 72 \\
\hline
\end{tabular}

NOTES:

'Switchers' are physicians who changed their SRI status between 1997 and 1998. Definitions of physician groups are explained in the text.

the SRI physicians is now negligible. These findings underscore the importance of carefully controlling for composition bias in our study. However, the findings also indicate that the composition bias probably cannot explain all of the observed change in exempt services, as the percentage changes for groups $\mathrm{B}$ and $\mathrm{C}$ remain quite large $(-27 \%$ and $-24 \%$, respectively).

\section{Results}

We present our results in two steps. First, we estimate the impact of the reform on the provision of services for each physician group to examine the relative merits of the profit maximization and literal income target hypotheses in predicting physician behaviour. Recall that the profit maximization hypothesis implies that physicians in group $\mathrm{C}$ will reduce their provision of exempt services and increase their provision of non-exempt services, while the income target hypothesis implies that physicians in this group will increase their provision of both types of service. In the second step, we directly estimate the own-price, cross-price, and income effects that are more useful for policy purposes if the physician behaviour falls between the two extreme cases of profit maximization and literal income target cases.

Table 4 shows the estimated impact of the reform for each physician group. The baseline model for each group of services includes a full set of control variables (age, gender, medical specialty, and location), and the sample includes provider physicians present in both sample years who did not switch their SRI status between 1997 and 1998. The reported coefficients are incidence ratios and represent the change in the services per physician between 1998 and 1997 for each treatment 
TABLE 4

Impact of the threshold reform on physician groups

\begin{tabular}{lcccr}
\hline & \multicolumn{4}{l}{$\begin{array}{l}\text { Dependent variable }=\text { number of services per physician, } \\
\text { negative binomial model, incidence rate ratios }\end{array}$} \\
\cline { 2 - 5 } Model & Group A & Group B & Group C & Sample \\
\hline Exempt services & 1.018 & $0.678^{* *}$ & $0.561^{*}$ & 10,862 \\
Non-exempt services & $(0.056)$ & $(0.061)$ & $(0.146)$ & \\
& 0.993 & 0.981 & 0.952 & 10,841 \\
& $(0.025)$ & $(0.028)$ & $(0.039)$ & \\
\hline
\end{tabular}

\section{NOTES}

The coefficients represent the change in services per physician between 1998 and 1997 for each treatment group of physicians relative to the SRI control group. Standard errors, in parentheses, are robust, adjusted for clustering by physicians, and refer to marginal coefficients. Both models include a quadratic in age, a gender indicator, 7 geographic indicators, and 33 indicators for medical specialties. ${ }^{* *}$ indicates significance at 0.05 level, and ${ }^{*}$ at 0.1 level.

group relative to the SRI control group. The standard errors are adjusted for clustering by physicians and refer to marginal coefficients.

The results for the exempt services indicate that the reform had no significant impact on physicians in group $\mathrm{A}$, while physicians in groups $\mathrm{B}$ and $\mathrm{C}$ significantly reduced their provision of exempt services. The results for the non-exempt services indicate that the reform had no significant impact for any group of physicians. We explored the sensitivity of these findings to variations in the model specification (including fixed physician effects), the sample selection rules (including physicians who did not provide any exempt services over the 1992-2004 period; including physicians who are present only in 1997), and different assignment rules (using 1996 rather than 1997 billings to assign physicians to groups). We also conducted a false experiment, which examined the change in the number of exempt services per physician between fiscal years 1996 and 1997. The results, presented in tables 2 and 3 in appendix B, indicate that our findings are quite robust to this battery of sensitivity tests: the impact of the reform is limited to the provision of exempt services, and then only for physicians in groups B and C.

Note that, as expected, these results are not strictly consistent with either of the polar cases of profit maximization or literal income target hypotheses. In other words, our findings suggest that the income effect is significant but not infinitely large.

In the next step, we directly estimate the income effects along with the ownprice and cross-price effects. The results are presented in table 5. The results for the baseline model for the exempt services are largely as expected: the own-price effect is significantly positive, the income effect is significantly negative, and the cross-price effect is negative although not significant. ${ }^{18}$ On the other hand, the

18 Recall that the own-price and cross-price effects are inversely related to coefficients reported in table 5 , as discussed in section 4 . 
TABLE 5

Estimated own-price, cross-price, and income effects

\begin{tabular}{|c|c|c|c|c|c|c|}
\hline Model & Group A & Group B & Group C & $\begin{array}{l}\text { Group } \\
\text { B-C }\end{array}$ & $\begin{array}{l}\text { Income } \\
\text { effect }\end{array}$ & $\begin{array}{l}\text { Sample } \\
\text { size }\end{array}$ \\
\hline Exempt services & & & $\begin{array}{l}\text { Own-price } \\
\text { effect }\end{array}$ & $\begin{array}{l}\text { Cross-price } \\
\text { effect }\end{array}$ & $\begin{array}{l}\text { Income } \\
\text { effect }\end{array}$ & \\
\hline Baseline model & $\begin{array}{c}1.017 \\
(0.055)\end{array}$ & $\begin{array}{c}0.463^{* *} \\
(0.068)\end{array}$ & $\begin{array}{c}0.459^{* *} \\
(0.126)\end{array}$ & $\begin{array}{l}1.008 \\
(0.277)\end{array}$ & $\begin{array}{c}0.99998^{* *} \\
(0.00001)\end{array}$ & 10,862 \\
\hline Score $>90$ th percentile & $\begin{array}{l}1.008 \\
(0.067)\end{array}$ & $\begin{array}{l}0.433^{* *} \\
(0.065)\end{array}$ & $\begin{array}{r}0.427^{*} \\
(0.145)\end{array}$ & $\begin{array}{l}1.015 \\
(0.345)\end{array}$ & $\begin{array}{l}0.999986^{* *} \\
(0.000004)\end{array}$ & 982 \\
\hline Excluding partial SRI & $\begin{array}{l}1.011 \\
(0.055)\end{array}$ & $\begin{array}{c}0.459^{* *} \\
(0.067)\end{array}$ & $\begin{array}{l}0.456^{* *} \\
(0.125)\end{array}$ & $\begin{array}{l}1.008 \\
(0.276)\end{array}$ & $\begin{array}{l}0.999983^{* *} \\
(0.000005)\end{array}$ & 10,856 \\
\hline Switchers as control group & $\begin{array}{c}0.788 \\
(0.102)\end{array}$ & $\begin{array}{c}0.381^{* *} \\
(0.075)\end{array}$ & $\begin{array}{c}0.356^{* *} \\
(0.107)\end{array}$ & $\begin{array}{c}1.071 \\
(0.293)\end{array}$ & $\begin{array}{c}0.999984^{* *} \\
(0.000005)\end{array}$ & 10,984 \\
\hline Non-exempt services & & & $\begin{array}{l}\text { Cross-price } \\
\text { effect }\end{array}$ & $\begin{array}{l}\text { Own-price } \\
\text { effect }\end{array}$ & $\begin{array}{l}\text { Income } \\
\text { effect }\end{array}$ & \\
\hline Baseline model & $\begin{array}{c}0.993 \\
(0.025)\end{array}$ & $\begin{array}{r}0.933^{*} \\
(0.028)\end{array}$ & $\begin{array}{c}0.945 \\
(0.039)\end{array}$ & $\begin{array}{c}0.987 \\
(0.037)\end{array}$ & $\begin{array}{l}0.9999984^{* *} \\
(0.0000004)\end{array}$ & 10,841 \\
\hline Score $>90$ th percentile & $\begin{array}{c}1.021 \\
(0.047)\end{array}$ & $\begin{array}{c}0.938 \\
(0.034)\end{array}$ & $\begin{array}{c}1.000 \\
(0.042)\end{array}$ & $\begin{array}{c}0.938^{*} \\
(0.035)\end{array}$ & $\begin{array}{c}0.9999991^{* *} \\
(0.0000003)\end{array}$ & 972 \\
\hline Excluding partial SRI & $\begin{array}{c}0.993 \\
(0.025)\end{array}$ & $\begin{array}{c}0.933^{*} \\
(0.028)\end{array}$ & $\begin{array}{c}0.945 \\
(0.039)\end{array}$ & $\begin{array}{c}0.987 \\
(0.037)\end{array}$ & $\begin{array}{c}0.9999984^{* *} \\
(0.0000004)\end{array}$ & 10,835 \\
\hline Switchers as control group & $\begin{array}{c}0.990 \\
(0.026)\end{array}$ & $\begin{array}{l}0.931^{*} \\
(0.029)\end{array}$ & $\begin{array}{c}0.943 \\
(0.039)\end{array}$ & $\begin{array}{c}0.987 \\
(0.037)\end{array}$ & $\begin{array}{c}0.9999984^{* *} \\
(0.0000005)\end{array}$ & 10,934 \\
\hline
\end{tabular}

NOTES

The coefficients are incidence rate ratios and represent the change in services per physician between 1998 and 1997 for each treatment group of physicians relative to the SRI control group. Standard errors, in parentheses, are robust, adjusted for clustering by physicians, and refer to marginal coefficients. Controls include a quadratic in age, a gender indicator, 7 geographic indicators, and 33 indicators for medical specialties. ${ }^{* *}$ indicates significance at 0.05 level, and ${ }^{*}$ at 0.1 level.

results for the baseline model for the non-exempt services indicate positive ownprice and cross-price effects, both of which are statistically insignificant, and a significantly negative income effect.

Table 5 also presents the results from three sensitivity tests, including only physicians with the matching score in the 90th percentile, excluding the partial SRI physicians from the control group, and including the switchers in the SRI control group. The results indicate that although the baseline estimates vary somewhat across different specifications, their sign and statistical significance are fairly consistent. Moreover, we explored the sensitivity of baseline results to similar variations in the model specification, the sample selection, and assignment rules, as we did for the baseline model without income effects in table 4 . We also estimated the models separately for each gender, age group (over or below the median age of 47 years), broad specialty group (general practitioners/family physicians, surgical specialists, and medical specialists), and for physicians located inside and outside the Toronto planning region. The results are presented in 
TABLE 6

Price elasticity and income effects for selected groups of exempt services

\begin{tabular}{|c|c|c|c|c|c|c|}
\hline $\begin{array}{l}\text { Group of } \\
\text { services }\end{array}$ & $\begin{array}{l}\text { Uncompensated } \\
\text { own-price } \\
\text { elasticity }\end{array}$ & $\begin{array}{l}\text { Compensated } \\
\text { own-price } \\
\text { elasticity }\end{array}$ & $\begin{array}{l}\text { Income } \\
\text { effect }\end{array}$ & $\begin{array}{l}\text { Compensated } \\
\text { cross-price } \\
\text { elasticity }\end{array}$ & $\begin{array}{l}\text { Sample } \\
\text { size }\end{array}$ & $\begin{array}{l}\text { Medical } \\
\text { specialties }\end{array}$ \\
\hline $\begin{array}{l}\text { All exempt } \\
\text { services }\end{array}$ & $0.102^{* *}$ & $0.206^{* *}$ & $-0.105^{* *}$ & -0.007 & 10,862 & All \\
\hline $\begin{array}{l}\text { Cataract } \\
\text { surgeries }\end{array}$ & $0.433^{* *}$ & $0.457^{* *}$ & $-0.023^{* *}$ & -0.110 & 411 & Ophthalmology \\
\hline Pacemakers & $1.052^{* *}$ & $1.091^{* *}$ & $-0.039^{* *}$ & $-0.598^{* *}$ & 632 & $\begin{array}{l}\text { Selected } \\
\quad \text { surgical and } \\
\text { medical }^{+}\end{array}$ \\
\hline Obstetrics & $0.232^{* *}$ & $0.409^{*}$ & $-0.177^{* *}$ & 0.070 & 5,118 & $\begin{array}{l}\text { Obstetrics, } \\
\text { general } \\
\text { practice }\end{array}$ \\
\hline Audiology & $0.934^{* *}$ & $1.043^{* *}$ & $-0.109^{* *}$ & $-0.468^{* *}$ & 524 & $\begin{array}{l}\text { Otolaryngology, } \\
\text { pediatrics }\end{array}$ \\
\hline Transplants & $0.403^{* *}$ & $0.505^{* *}$ & $-0.103^{* *}$ & $-0.205^{* *}$ & 1,779 & All surgical ${ }^{++}$ \\
\hline Surgery & $0.383^{* *}$ & $0.528^{* *}$ & $-0.145^{* *}$ & $-0.118^{* *}$ & 1,779 & All surgical ${ }^{++}$ \\
\hline
\end{tabular}

NOTES

Income effect is the income elasticity multiplied by the share of specific services in total billings for exempt services. The uncompensated own-price elasticity is the sum of compensated own-price elasticity and income effect. + Includes General Surgery, Cardiovascular and Thoracic Surgery, Internal Medicine, and Cardiology. ++ Includes General Surgery, Neurosurgery, Orthopedic Surgery, Plastic Surgery, Cardiovascular and Thoracic Surgery, Obstetrics and Gynecology, Ophthalmology, Otolaryngology, and General Thoracic Surgery. ${ }^{* *}$ indicates significance at 0.05 level, and ${ }^{*}$ at 0.1 level.

tables 4-7 in appendix B and paint a fairly consistent picture: the income effects are significantly negative in most specifications for both types of services, the own-price effects are positive but significant only for the exempt services, and the cross-price effects are mainly insignificant.

Lastly, we estimated the income and price effects for selected groups of exempt and non-exempt services to explore the impact of aggregation on our results. ${ }^{19,20}$ The estimates are presented in appendix B, and the implied price elasticities and income effects are shown in tables 6 and $7 .{ }^{21}$

For the exempt services in table 6, the compensated own-price elasticity is positive and significant for all groups of services and ranges between 0.2 and 1.1. The income effect is consistently negative and significant, although it is quite small, ranging between -0.02 and -0.18 . These two results imply that the

19 The choice of specific groups of services is limited by the fact that the SRI physicians do not provide all types of services and that the sample size for some groups of services is quite small.

20 In these regressions, the income measure is multiplied by the share of particular service in the total billings for the relevant group of services. For example, the income measure for cataracts is multiplied by 0.36 , the share of cataracts in the total billings for the group of exempt services.

21 The elasticities are calculated at the mean values of prices and non-labour income for physicians in groups B and C. The mean non-labour income is assumed to be $10 \%$ of the physician practice income. This assumption is consistent with the estimates we obtained from the 2001 Census, which indicate that income sources other than wages and salary represent about $8 \%$ of total income for active physicians. 
TABLE 7

Price elasticity and income effects for selected groups of non-exempt services

\begin{tabular}{|c|c|c|c|c|c|}
\hline $\begin{array}{l}\text { Group of } \\
\text { services }\end{array}$ & $\begin{array}{l}\text { Uncompensated } \\
\text { own-price } \\
\text { elasticity }\end{array}$ & $\begin{array}{l}\text { Compensated } \\
\text { own-price } \\
\text { elasticity }\end{array}$ & $\begin{array}{l}\text { Income } \\
\text { effect }\end{array}$ & $\begin{array}{l}\text { Compensated } \\
\text { cross-price } \\
\text { elasticity }\end{array}$ & $\begin{array}{l}\text { Sample } \\
\text { size }\end{array}$ \\
\hline All non-exempt services & -0.031 & 0.024 & $-0.055^{* *}$ & 0.110 & 10,841 \\
\hline Office visits & $0.042^{*}$ & $0.043^{*}$ & -0.001 & 0.011 & 10,557 \\
\hline Hospital visits & $0.155^{* *}$ & $0.417^{* *}$ & $-0.262^{* *}$ & -0.036 & 9,230 \\
\hline $\begin{array}{l}\text { Pulmonary function studies, } \\
\text { diagnostic ultrasound, } \\
\text { nuclear medicine, } \\
\text { diagnostic radiological } \\
\text { examination }\end{array}$ & 0.031 & 0.034 & -0.003 & 0.067 & 3,625 \\
\hline $\begin{array}{l}\text { Health examination, } \\
\text { psychotherapy, } \\
\text { counselling }\end{array}$ & $-0.260^{* *}$ & $0.144^{*}$ & $-0.405^{* *}$ & $0.313^{* *}$ & 8,634 \\
\hline Obstetrical care & -0.031 & 0.020 & $-0.051^{* *}$ & 0.070 & 6,363 \\
\hline $\begin{array}{l}\text { Integumentary, } \\
\text { musculoskeletal, } \\
\text { cardiovascular, haemic, } \\
\text { and lymphatic systems }\end{array}$ & $0.667^{* *}$ & $0.951^{* *}$ & $-0.284^{* *}$ & 0.392 & 1,068 \\
\hline $\begin{array}{l}\text { Digestive, urogenital, } \\
\text { urinary, male genital, } \\
\text { female genital, and } \\
\text { endocrine systems }\end{array}$ & $-0.432^{*}$ & -0.258 & $-0.174^{* *}$ & -0.283 & 5,652 \\
\hline
\end{tabular}

NOTES

Income effect is the income elasticity multiplied by the share of specific services in total billings for non-exempt services. The uncompensated own-price elasticity is the sum of compensated own-price elasticity and income effect. ${ }^{* *}$ indicates significance at 0.05 level, and ${ }^{*}$ at 0.1 level.

uncompensated price elasticity is positive for all groups of exempt services. For the non-exempt services in table 7, the compensated own-price elasticity is mainly positive. For the significant estimates, it ranges between 0.04 and 0.9 . The income effect is consistently negative and mainly significant. For the significant estimates, it ranges between -0.05 and -0.4 . It is interesting to note that for some services the income effect dominates the own-price effect and the uncompensated price elasticity is actually negative. However, for most services the uncompensated price elasticity is either significantly positive or insignificant. Lastly, the cross-price elasticity is negative and significant for many exempt services, but it is mainly insignificant for non-exempt services.

We conclude this section by reflecting on main implications of our results for the study of physician labour supply behaviour. First, our results are fairly consistent with several predictions from a simple model of physician labour supply. For example, physicians in group A were not affected by the reform at all, as predicted by the model. In addition, the estimated own-price elasticity and income effects are mostly significant and have theoretically correct signs. The results for the cross-price effects are also mainly significant with correct signs, but only for the exempt services; for the non-exempt services, these effects are generally insignificant. 
Second, our results indicate significant but small income effects. Therefore, as expected, neither the profit maximization nor the literal target income hypothesis represents an adequate description of physician behaviour. In addition, the income elasticity is always smaller than the own-price elasticity for the exempt services. The 'perverse' cases of negatively sloped supply curves arise only for a minority of non-exempt services.

Third, our results indicate that the cross-price effects tend to be significant only for the exempt services. Therefore, the spillover effect should be of a greater policy concern when fees for non-exempt services are changed, compared with fee changes for exempt services.

Lastly, the exempt and non-exempt services in our study differ systematically in terms of their relative prices and volumes. This suggests that our findings may be useful for future policy decisions because of the possible relation between these easily measurable characteristics of services and their own-price and cross-price elasticities. The extent to which this extrapolation is valid remains to be confirmed by future research.

\section{Conclusion}

Understanding how physicians respond to fee changes is an important yet intricate policy question. Because economic theory predicts that the physician response depends on the relative strength of opposing income and substitution effects, the question remains to be answered empirically. In this paper, we examine a reform to the physician threshold reform in Ontario that facilitates a treatment-control approach to isolate the impact of fee change, free from biases that potentially affect simple time-series or cross-section inference. We find that the income effect is small but significant, which refutes the profit maximization hypothesis (no income effects) and the literal target income hypothesis (infinitely large income effects) as adequate descriptions of physician behaviour. Our estimates also indicate that the perverse case of negatively sloped supply curves arises only for a minority of services with relatively lower prices and higher volumes. For services with relatively higher prices and lower volumes, the substitution effect always dominates the income effect. In addition, we find that the cross-price effect is significant only for the latter group of services. These findings may be used to guide future policy making.

Our study admittedly takes only the first few steps in improving our understanding of how physicians respond to fee changes and the impact of the threshold system on physician behaviour. Many questions remain to be answered, including the welfare implications of the threshold system. As we document in this paper, reforms to the threshold system have the ability to influence physician behaviour through their impact on relative fees and can be an effective tool in controlling payments to physicians. But ultimately, the question is what effect such reforms may have on health outcomes. 


\section{References}

Autor, David, and David Scarborough (2004) 'Will job testing harm minority workers?' Working Paper No. 10763, National Bureau of Economic Research

Autor, David, John Donohue, and Stewart Schwab (2003) 'The costs of wrongful-discharge laws,' Working Paper No. 9425, National Bureau of Economic Research

Beegle, Kathleen, and Wendy Stock (2003) 'The labor market effects of disability discrimination laws,' Journal of Human Resources 38, 806-59

Brown, Douglas (1988) 'Do physicians underutilize aides?' Journal of Human Resources $23,342-55$

Dowdall, Catherine, and Lorna Ramchandar (1999) 'The application of physician billing thresholds in Ontario and across Canada,' Ontario Medical Review, 17-25

Emery, John, Christopher Auld, and Mingshan Lu (1999) 'Paying for physician services in Canada: the institutional, historical, and policy contexts,' Institute for Health Economics, Edmonton

Greene, William (1994) 'Accounting for excess zeros and sample selection in Poisson and negative binomial regression models,' Working Paper EC-94-10, Department of Economics, New York University

Grootendorst, Paul (1995) 'A comparison of alternative models of prescription drug utilization,' Health Economics 4, 183-98

Hausman, Jerry (1985) 'The econometrics of non-linear budget sets,' Econometrica 53, 1255-82

Hurley, Jerry, Roberta Labelle, and Thomas Rice (1990) 'The relationship between physician fees and the utilization of medical services in Ontario,' Advances in Health Economics and Health Services Research 11, 49-78

Jones, Andrew (2000) 'Health econometrics,' in Handbook of Health Economics, Vol. 1, ed. A.L. Culyer and J.P. Newhouse (Amsterdam: North-Holland)

Mas, Alexandre (2004) 'Do disappoint pay raises lower productivity? Final offer arbitration and the performance of New Jersey police officers,' working paper, University of California at Berkeley

McGuire, Thomas (2000) 'Physician agency,' in Handbook of Health Economics, Vol. 1, ed. A.L. Culyer and J.P. Newhouse (Amsterdam: North-Holland)

McGuire, Thomas, and Mark Pauly (1991) 'Physician response to fee changes with multiple payers,' Journal of Health Economics 10, 385-410

Mitchell, Jean, Jack Hadley, and Darrel Gaskin (2000) 'Physicians' responses to Medicare fee schedule reductions,' Medical Care 38, 1029-39

- (2002) 'Spillover effects of Medicare fee reductions: evidence from ophthalmology,' International Journal of Health Care Finance and Economics 2, 171-88

Moffitt, Robert (1986) 'The econometrics of piecewise-linear budget constraints: a survey and exposition of the maximum likelihood method,' Journal of Business and Economic Statistics 4, 317-28

- (1990) 'The econometrics of kinked budget constraints,' Journal of Economic Perspectives 4, 119-39

Reinhardt, Uwe (1972) 'A production function for physician services,' Review of Economics and Statistics 54, 55-66

Rice, Thomas (1983) 'The impact of changing Medicare reimbursement rates on physicianinduced demand,' Medical Care 21, 803-15

Rice, Thomas, Sally Stearns, Donal Pathman, Susan DesHarnais, Michelle Brasure, and Ming Tai-Seale (1999) 'A tale of two bounties: the impact of competing fees on physician behaviour,' Journal of Health Politics, Policy, and Law 24, 1307-30

Rizzo, John, and David Blumenthal (1994) 'Physician labor supply: do income effects matter?' Journal of Health Economics 13, 433-53 
1284 J. Kantarevic, B. Kralj, and D. Weinkauf

Tai-Seale, Ming, Thomas Rice, and Sally Stearns (1998) 'Volume responses to Medicare payment reductions with multiple payers: a test of the McGuire-Pauly model,' Health Economics 7, 199-219

Thurnton, James (1998) 'Do physicians employ aides efficiently? Some new evidence on solo practitioners,' Journal of Economics and Finance 22, 85-96

Yip, Winnie (1998) 'Physician response to Medicare fee reductions: changes in the volume of coronary artery bypass graft surgeries in the Medicare and private sectors,' Journal of Health Economics 17, 675-99 